\title{
Invited review: Understanding the behavior of caseins in milk concentrates
}

\author{
Milena Corredig, ${ }^{1,2 *}$ Pulari Krishnakutty Nair, ${ }^{3}$ Ying $\mathrm{Li}^{4}{ }^{4}$ Hadi Eshpari, ${ }^{1} \dagger$ and Zhengtao Zhao ${ }^{1} \ddagger$ \\ ${ }^{1}$ Food Science Department, University of Guelph, Guelph, Ontario, Canada N1G2W1 \\ ${ }^{2}$ iFood Center for Innovative Food, Food Science Department, Aarhus University, Blichers Alle 20, Tjele 8830, Denmark \\ ${ }^{3}$ Gay Lea Foods Cooperative Limited, Guelph, Ontario, Canada N1H1J5 \\ ${ }^{4}$ Parmalat Canada Limited, Operations, Winchester, Ontario, Canada KOC 2KO
}

\section{ABSTRACT}

The colloidal properties of the casein micelles play a major role in the structural properties of milk protein concentrates. Because of their great technological importance, the structural-functional relationships of casein micelles have been studied for decades in skim milk; however, novel ingredients are now available with higher protein concentrations and varying in composition. The colloidal behavior of caseins in these systems is not fully understood. Concentrates prepared with membrane technologies, and subjected to pre- or postmodifications that affect their technological functionality, have become increasingly widespread. This has created large opportunities for innovation and generation of value-added ingredients. The manner in which caseins interact with themselves and the other components in these concentrates will affect the structure of the final matrix. During concentration by filtration, the interparticle distance between the micelles decreases considerably, increasing their spatial correlation and decreasing their diffusivity. Rearrangements occur due to changes in environmental conditions, such as ionic composition, osmotic stress, shear, $\mathrm{pH}$, or heating temperature. This will have important consequences on bulk viscosity of the concentrates, as well as on the mode of formation of structures' building blocks. This paper aims at highlighting some of the important factors affecting the colloidal structure of casein micelles, their destabilization and network formation, namely, processing history, volume fraction, composition of the serum phase, and ionic equilibrium. Understanding these factors will lead to a better quality control of dairy ingredients and to the development of a new generation of ingredients with targeted functionality.

Received November 4, 2018.

Accepted February 7, 2019.

*Corresponding author: mc@food.au.dk

$\dagger$ Current address: H. Eshpari, Tillamook County Creamery Association, 1400 NW 22nd Ave., Portland, OR 97210.

$\ddagger$ Current address: Z. Zhao, Parmalat Canada Limited, R\&D, London, Ontario, Canada N6B1N8.
Key words: casein micelle, milk protein concentrate, dairy ingredient, membrane technology

\section{INTRODUCTION}

Milk proteins are major drivers of structure formation in dairy products. Caseins make up about $80 \%$ of the total protein content in milk, with the remainder being whey proteins. Caseins self-assemble in colloidal structures referred to as casein micelles and make up about $10 \%$ of the volume in skim milk (Holt, 1992; Horne, 2003). By understanding and predicting their colloidal behavior during processing, it is possible to modulate their technological functionality when used as key ingredients for structuring dairy matrices.

Four types of caseins are mainly present in bovine milk: $\alpha_{S 1}, \alpha_{S 2}, \beta$, and $\kappa$. These rheomorphic proteins adapt their structure to changes in environmental conditions (Holt et al., 2013) and assemble to form colloidal aggregates, called casein micelles, with a diameter ranging from 50 to $300 \mathrm{~nm}$ (Dalgleish, 2011). Phosphate and calcium ions constitute about $8 \%$ of the total mass of the casein micelles (Holt, 2004; De Kruif et al., 2012). The presence of calcium phosphate clusters in the micelles is of critical importance to the structure of the protein particles as well as their technological functionality (De Kruif et al., 2012; Dalgleish and Corredig, 2012). The colloidal calcium phosphate, associated with the micellar proteins, is in dynamic equilibrium with the minerals in the serum phase (Le Graët and Gaucheron, 1999; Holt, 2004).

In contrast, the most abundant whey proteins are $\alpha$-LA and $\beta$-LG, making up 25 and $65 \%$ of the total whey protein in milk, respectively. These globular proteins, when heated at temperatures above $70^{\circ} \mathrm{C}$, modify their structure, expose reactive groups, and form aggregates with one another and with the caseins in milk (Anema and Li, 2003; Donato and Dalgleish, 2006). These reactions are dependent on environmental conditions and temperature, and the type and concentration of heat induced complexes will help modulate the viscoelasticity and structure of the final dairy network. 
The casein micelles are highly hydrated colloidal particles, containing approximately $3.5 \mathrm{~mL}$ of water per gram of protein (Morris et al., 2000; Dalgleish, 2011; Huppertz et al., 2017). $\kappa$-Casein, present in a glycosylated form, protrudes in the aqueous phase forming a highly hydrated polyelectrolyte layer, imparting steric and electrostatic stability (De Kruif and Zhulina, 1996). This $\mathrm{k}-\mathrm{CN}$ brush is more hydrated than the core (Huppertz et al., 2017). The inner core of the casein micelles is constituted of protein dense regions and more hydrated pockets (Dalgleish, 2011; Huppertz et al., 2017). Rearrangements of the supramolecular structure of the micelles may occur during concentration, due to changes in interparticle distance, as well as environmental changes such as $\mathrm{pH}$ or ionic composition.

By decreasing the repulsive forces, which provide colloidal stability to the micelles, it is possible to induce aggregation and the formation of a particle network, and to create the texture and structures so familiar in dairy products (Dalgleish and Corredig, 2012). Caseins can be destabilized, for example, using chymosin in the presence of calcium, or by acidification. The coagulation of milk using chymosin is an essential step in the making of cheese. The reaction is a specific hydrolysis affecting the $\kappa-\mathrm{CN}$ stabilizing layer, and it includes 2 overlapping stages (De Kruif, 1992; Sandra et al., 2007). The primary stage is the enzymatic cleavage of $\kappa-\mathrm{CN}$. Once a sufficient amount of protein has been hydrolyzed, aggregation occurs. In untreated skim milk at native $\mathrm{pH}$, the second stage of the reaction, the formation of a casein network, occurs when at least 85 to $90 \%$ of the casein-macropeptide is released into solution (Sandra et al., 2007). The aggregation is calcium dependent. In reconstituted milk protein concentrates (MPC), the contribution of free calcium to the formation of a gel network is critical and addition of sufficient calcium is necessary to restore the rennet coagulation kinetics and gel strength (Martin et al., 2010; Sandra and Corredig, 2013).

Another common mechanism employed to form gels in dairy matrices is the modification of the micelles' surface charge by changes in $\mathrm{pH}$. During acidification, the proteins' negative charges decrease gradually, and the calcium phosphate nanoclusters associated with the phosphoserine AA in the interior of the micelles are progressively diffused into the serum. A complete release occurs at a $\mathrm{pH}$ around 5.0 (Le Graët and Gaucheron, 1999). The change in $\mathrm{pH}$ causes the collapse of the $\kappa$-CN hairy layer, so that steric and electrostatic stabilization are diminished and micelles start to aggregate as they approach their isoelectric point $(\mathrm{pH} \sim 4.6$; Dalgleish et al., 2004). In acid-induced gels, the casein particles maintain their individuality in the gel network, as the micelles are still covered by the glycosylated por- tion of $\kappa-C N$ (De Kruif, 1998). In milk that has been extensively heat treated, the linkages between casein particles are reinforced by heat-induced whey protein aggregates bridges (Lucey et al., 1998; Donato et al., 2007). In acid gels made with heated milk, a higher $\mathrm{pH}$ of gelation is shown, and the network formed is much stiffer than in unheated milk gels (Lucey et al., 1998; Donato et al., 2007). This is not the case for enzymatically induced destabilization, where the mechanism is based on a decrease of steric repulsion forces because of the hydrolysis of the glycosylated moieties of $\kappa-\mathrm{CN}$ (Sandra et al., 2007). In this case, the presence of heat induced complexes interacting with the $\kappa-\mathrm{CN}$ on the surface of the micelles will inhibit aggregation (Kethireddipalli et al., 2011).

\section{Concentration of Milk}

Studies on concentrated milk have been conducted by reconstituting skim milk powder, using evaporated milk, or by using retentates (fresh or reconstituted) obtained by membrane filtration. It is generally assumed that the overall supramolecular assembly of the casein micelles is unchanged during concentration, but the processing properties of the concentrates vary depending on their processing history and overall composition. Factors affecting protein-protein interactions and calcium binding via phosphorylated clusters, which are key to the structure of the micelles (Lucey and Horne, 2018), will alter functionality. Other factors will also be critical, for example, free ion activity, the volume fraction occupied by the casein micelles in the concentrate, and the degree of denaturation of the whey proteins.

For optimal utilization of MPC as functional ingredients, the processing history and environmental conditions need to be known in detail. This applies for both fresh as well as systems reconstituted after drying. In reconstituted systems, there is an additional opportunity to modify functionality, by manipulating solvent conditions (Sandra and Corredig, 2013; Lin et al., 2018).

Concentration by evaporation maintains the protein to other solids ratio in the concentrates. This process is often combined with mild heating under vacuum, and because of energy consumption, reverse osmosis is increasingly being explored as an alternative method of concentration of skim milk. In contrast to traditional evaporation, concentration using membrane filtration selectively retains certain milk components, depending on the properties of the membrane, with full transmission of others in the permeate fraction. The membrane characteristics, such as pore size, chemistry, and rejection properties, will affect the composition of the final MPC. Ultrafiltration is a pressure-driven membrane 
process in which membranes having molecular weight cut-off ranging from 2 to $100 \mathrm{kDa}$ are commonly employed to obtain MPC for further processing. The UF membranes retain most of the proteins and allow permeation of small molecular weight solutes (i.e., lactose and soluble minerals). Filtration membranes of pore size smaller than UF, namely, nanofiltration or reverse osmosis, are also able to retain and concentrate proteins as well as small soluble compounds, and are often used as means to prepare concentrated milk ingredients for further processing, to partly demineralize (nanofiltration), and to decrease transport costs. Recently, the use of pore sizes larger than those conventionally used for UF concentration is becoming widespread. In a process normally referred to as microfiltration, a larger nominal pore size is used, so that not only small molecular weight solutes, but also serum proteins are transmitted through the membrane. This process creates a new group of protein concentrates (also called micellar casein concentrates) where the protein fraction is characterized by varying ratios of caseins to whey proteins. Finally, it is important to mention the use of diafiltration (DF), the process of adding water during membrane filtration, to improve permeation flow and increase the transmission of compounds through the membranes. With DF, the ratio of colloidal to free ions may be significantly altered, depending on the extent of water addition and concentration ratio (Ferrer et al., 2011; Li and Corredig, 2014).

Spray-dried MPC powders obtained after membrane filtration range in protein concentration from 35 to more than $85 \mathrm{~g}$ per $100 \mathrm{~g}$ of solids, with a corresponding decrease in the amount of lactose and minerals, depending on the extent of concentration and DF. The solubility of the MPC powders differs substantially, depending on processing conditions, protein concentration, ionic composition (Crowley et al., 2015a).

It is not possible to talk about concentration without mentioning calcium phosphate equilibrium in milk, as this equilibrium is fundamental to stability of the casein micelles (Holt, 2004; Lucey and Horne, 2018). In milk, approximately one-third of the calcium, one-half of the inorganic phosphate, and most of the magnesium and citrate are diffusible through a semi-permeable membrane with pore size less than $10 \mathrm{kDa}$ (Holt, 2004). During UF these ions will permeate, and only the colloidal calcium phosphate and any other ions associated with the proteins will be selectively concentrated in the retentates. Calcium phosphate nanoclusters appear to remain intact during concentration by UF, in the absence of water addition (without DF; Ferrer et al., 2011; $\mathrm{Li}$ and Corredig, 2014). Attention to the changes in calcium phosphate equilibrium in milk concentrates cannot be stressed enough. Colloidal calcium phosphate seems to be a major factor in the techno-functional properties of the micelles, for example, the melting properties or stretchability of cheese (Choi et al., 2007; Lucey and Horne, 2018). Furthermore, it has been demonstrated that by changing the mineral equilibrium it is possible to modify the interactions between the caseins during spray drying with consequences on their reconstitution properties (Shuck et al., 2002; Havea, 2006; Schokker et al., 2011; Sikand et al., 2013; Lin et al., 2018). For example, replacing $30 \%$ of calcium with sodium during concentration results in improved hydration of the reconstituted MPC powders (Sikand et al., 2013), and demineralization of concentrates by pre-acidification of skim milk before membrane filtration has also shown significant changes to MPC functionality, such as solubility or gelling properties (Eshpari et al., 2014; Liu et al., 2019).

\section{Colloidal Properties of Casein Micelles in Concentrated Milk Suspensions}

With the utilization of MPC as ingredients in dairy products, interest has increased in understanding the effect of protein concentration on the bulk properties of milk concentrates, isolates, or casein micelle suspensions and their properties during reconstitution (Karlsson et al., 2005; Crowley et al., 2015a; Gazi and Huppertz, 2015). Regardless of the mode of concentration, the viscosity of casein micelle suspensions increases with concentration, with a dramatic change from a Newtonian to a non-Newtonian behavior (Karlsson et al., 2007; Dahbi et al., 2010; Krishnakutti Nair et al., 2014). Similarly, the viscosity of reconstituted MPC also increases with protein concentration, and it can be altered by modifications to the serum (Deshpande and Walsh, 2018; Lin et al., 2018). The semi-empirical equation has been used to describe the dependence of viscosity as a function of concentration, with a maximum packing volume fraction for casein micelles of about 0.79 (Snoeren et al., 1982). The volume fraction is defined as the concentration of protein $(\mathrm{g} / \mathrm{mL})$ and its voluminosity $(\mathrm{mL} / \mathrm{g})$, calculated as for hard spheres of comparable diameter. In skim milk, the volume fraction $(\phi)$ occupied by the casein micelles is 0.1. The voluminosity of casein micelles ranges in the literature between 3.4 and $4.4 \mathrm{~mL} / \mathrm{g}$ (Walstra, 1979; Morris et al., 2000; Nöbel et al., 2012).

As concentration increases, the micelle inter-particle distance and diffusivity decreases. For example, at a $\phi$ of about 0.2 , corresponding to about $2 \times$ concentration, their inter-micellar distances are approximately equal to the average micelle diameter (Karlsson et al., 2005). The bulk rheological properties have been modeled, in the literature, as for a suspension of hard spheres. 
However, it is important to point out that the micelles are highly solvated protein assemblies. A portion of the water associated with the micelles (about $20-30 \%$ ) is located in the outer polyelectrolyte brush layer (Huppertz et al., 2017). The core, is an open, porous structure characterized by protein-dense and water-rich patches (Dalgleish, 2011). The ionic environment is a critical factor affecting the steric and electrostatic interactions between the casein micelles. With concentration methods such as evaporation and reverse osmosis, the free ions are also concentrated, with membrane filtration there is a depletion of soluble components, which allows reaching higher ratios of proteins/ions in the final concentrate, compared with evaporated milk concentrates. The bulk viscosity as a function of volume fraction is then dependent on changes occurring to the continuous phase in which the interacting micelles are dispersed (Krishnakutti Nair et al., 2014; Zhao and Corredig, $2016 a, b)$. The critical value of volume fraction where the micelles lose their native colloidal structure, their voluminosity, and show rearrangements of structure or a collapse of the hairy layer, is still open to debate (Bouchoux et al., 2009a,b, 2010; Qu et al., 2015). Studies on concentrated casein micelle suspensions have been carried out using reconstituted MPC or micellar concentrates (Bouchoux et al., 2009a,b; Dahbi et al., 2010), fresh milk retentates, or concentrated suspensions obtained by osmotic stressing (Karlsson et al., 2005; Krishnakutti Nair et al., 2013, 2014; Zhao and Corredig 2016a,b). It is critical to know the details of the processing history of the concentrates to compare literature results.

During evaporation, water is preferentially removed from the serum phase. The soluble caseins and calcium in the serum phase decrease as a function of increasing concentration, shifting to the colloidal phase (Liu et al., 2012). The ionic fraction is also concentrated. Casein micelles are significantly affected by evaporative concentration and the changes are not fully reversible (Liu et al., 2012). This is not the case during concentration by membrane filtration, as the ionic concentration of the serum phase remains unaltered, unless DF is conducted, when the free ion concentration in the serum phase is drastically decreased. With a decrease in the soluble calcium fraction, diafiltered milk concentrates also show a slight decrease of the colloidal calcium phosphate fraction associated with the micelles (Ferrer et al., 2011; Li and Corredig, 2014). This decrease can be attributed to a dissociation of micellar casein, as well as a solubilization of the colloidal calcium phosphate. The turbidity of milk increases in diafiltered milk compared with ultrafiltered milk, due to differences in the refractive index contrast between the casein micelles and the serum phase (Ferrer et al., 2011).
Osmotic stressing has been employed as a method to concentrate casein micelle suspensions in situ to high volume fractions and observe the changes in their colloidal properties (Bouchoux et al., 2009a, 2010; Krishnakutti Nair et al., 2013, 2014). These studies demonstrated that the behavior of casein micelle suspensions was equivalent to that of hard sphere models. A phosphocaseinate fraction (obtained by microfiltration of milk, depleted of whey protein) was used in some of the studies (Bouchoux et al., 2009b, 2010; Dahbi et al., 2010). The authors identified 4 concentration regimens. At $\phi$ values $<0.25$ there is very little concentration dependence on viscosity, and the micelles show a free diffusing behavior. At concentrations $>2 \times$, the contact between neighboring protein particles weakens, and this was attributed to the weakening of inter-micellar brush repulsion forces (Qu et al., 2015). At $\phi<0.54$, the casein micelles can be considered as incompressible hard spheres, but with a strong dependence of the viscosity on concentration. At a higher volume fraction, the viscosity shows a steep increase, with a divergence at a volume fraction $>0.69$ where the casein micelles are described as jammed (Dahbi et al., 2010).

All these studies were performed with phosphocaseinate micellar suspensions. Strong interactions are noted between casein micelle at concentrations of about 125 $\mathrm{g} / \mathrm{L}$ (corresponding to approximately $5.5 \times$ milk concentration), and a phase transition from sol to gel is observed, with jamming at a concentration of about $180 \mathrm{~g} / \mathrm{L}$ (Bouchoux et al., 2009a). In the range between $\phi 0.54$ and 0.61, Dahbi et al. (2010) reported a viscosity plateau as a function of concentration. They described the plateau as the point where at such high volume fraction, the casein micelles may become somewhat compressible, allowing for interpenetration of the $\kappa$-CN layer, leading to a smaller than observed volume fraction (Bouchoux et al., 2009a; Dahbi et al., 2010). The plateau observed in phosphocaseinate suspensions (Dahbi et al., 2010) was not observed in casein suspensions from fresh milk (Krishnakutti Nair et al., 2014). In this case, the balance between repulsive and attractive forces may lead to internal rearrangements of the protein structures and a partial release of casein molecules into the soluble phase.

At very high volume fractions, $>0.64$, hard uncompressible spheres reach the maximum packing volume, and at a volume fraction of 0.78 the interstitial spaces between the casein micelle suspensions have been shown to reach minimum values (Bouchoux et al., 2010). At $\phi$ values of 1 , small angle X-ray scattering observations suggest that the casein micelles are in direct contact with each other and that the remaining inter-micellar voids represent only $5 \%$ of the total volume (Bouchoux et al., 2010; Qu et al., 2015). The X-ray scattering data 
also suggest that at this concentration the micelles are not yet compressed. This may be due to the polydisperse nature of the casein micelle suspension. Samples re-dispersed after these high volume fractions show particles with identical shape and size to those observed in the original samples (Krishnakutti Nair et al., 2014) and with a composition similar to that of casein micelles in terms of structure and mass (Qu et al., 2015).

Similar experiments were conducted with casein micelle suspensions prepared by osmotic stressing of untreated skim milk, and confirmed the behavior described with phosphocaseinate suspensions (Krishnakutti Nair et al., 2013, 2014). Figure 1 reports data on relative viscosity as a function of volume fraction from fresh milk, and not resuspended phosphocaseinate. The casein micelles diffuse freely up to 0.3 volume fraction and show restricted motion at higher concentrations because of their small intermicellar distance. Serum composition analysis demonstrated that at high volume fractions a release of colloidal calcium phosphate occurs in the serum phase, with little apparent disruption of the structure of the casein micelles (Krishnakutti Nair et al., 2013). As shown in Figure 1, the relative viscosity of untreated casein micelles, at a volume fraction below 0.6 , show 3 distinct regimens, a dilution, a transition, and a concentrated regimen for uncompressible spheres (Krishnankutti Nair et al., 2013, 2014).

A similar behavior was also shown for casein micelles concentrated by osmotic stress from milk heated at $90^{\circ} \mathrm{C}$ for $10 \mathrm{~min}$. Concentrating the micelle suspensions from milk heated at various $\mathrm{pH}$ values as well as with $\mathrm{NaCl}$ concentrations up to $300 \mathrm{~m} M$ still shows changes

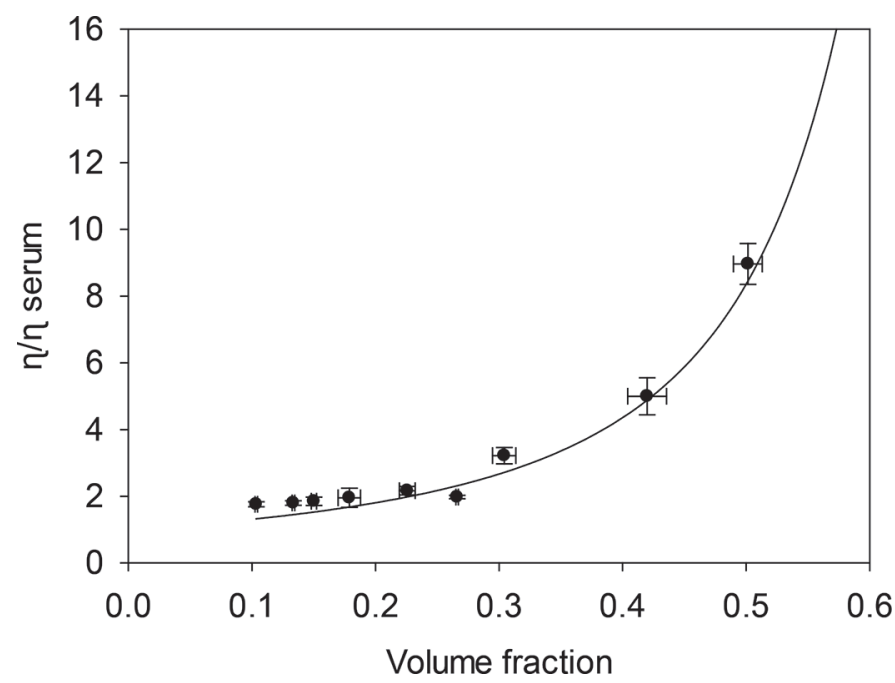

Figure 1. Relative viscosity $\left(\eta / \eta\right.$ serum), measured at $300 \mathrm{~s}^{-1}$ for untreated milk as a function of volume fraction, with bars representing SD. The line corresponds to the calculated fit using the Mendoza model for interacting colloidal spheres (Mendoza and SantamaríaHolek, 2009). in relative viscosity versus volume fraction that can be modeled to hard sphere behavior, assuming no changes in the compressibility of the micelles (Krishnakutti Nair et al., 2013; Zhao and Corredig, 2016b). It is important to note that there was an increase in the viscosity of the continuous phase, defined as the fraction unsedimentable after ultracentrifugation at 100,000 $\times$ $g$ for $1 \mathrm{~h}$ at $20^{\circ} \mathrm{C}$, as a function of concentration factor (Krishnakutti Nair et al., 2013, 2014; Zhao and Corredig, 2016a). This was due to an increase in the protein concentration in the soluble phase (Krishnakutti Nair et al., 2014). It was also concluded that in the presence of sodium chloride the casein micelles undergo some internal rearrangements, noted by a significant increase in protein and free calcium phosphate in the unsedimentable serum phase (Zhao and Corredig 2016a).

The increase in relative viscosity as a function of concentration can no longer be modeled after the behavior of interacting hard spheres when milk is adjusted to $\mathrm{pH}$ below 6.8 before concentration (Zhao and Corredig, 2016b). The deviation from hard sphere behavior can be explained by changes in the compressibility of the micelles at a certain volume fraction, as well as increased interparticle interactions, and possible variations of voluminosity, size, and shape as a function of concentration (Zhao and Corredig, 2016b).

Little has been reported on the effect of shear on the supramolecular structure of the casein micelles during concentration. In a recent work, the surface reactivity of casein micelles to chymosin was observed as a means to identify possible surface rearrangements during concentration by UF compared with osmotic stressing, where minimum shear is applied. In spite of the identical composition of the concentrates, the diffusivity of the casein micelles, measured by light scattering, was significantly different between the 2 suspensions. Drastic differences were also present in the reactivity of the casein micelle suspensions after the addition of sodium caseinate (Krishnakutti Nair and Corredig, 2015). This may indicate that during concentration by UF, although the bulk viscosity can be modeled after the behavior of hard spheres after taking into consideration hydrodynamic interactions (Mendoza and SantamaríaHolek, 2009), rearrangements occur to the internal structure, which cause some release of micellar caseins in the serum phase and some surface modifications not noted during the more gentle concentration by osmotic stressing.

Casein dissociation has recently been evaluated as a novel approach to improve the functional properties of reconstituted MPC. In particular, the effect of pre-acidification, the use of calcium chelating agents, or changes in salt balance have been studied on changes in solubility and functionality of milk concentrates (Eshpari et 
al., 2014, 2015; Marella et al., 2015; Ramachandran et al., 2017; Liu et al., 2019). Further changes in the ionic composition of the serum phase during reconstitution can also affect the solubility and functional properties (i.e., gelation, heat stability) of concentrates (Crowley et al., 2015b; Lin et al., 2018).

\section{Heat Stability in Concentrated Systems}

Heat treatment of milk concentrates leads to physical instability, precipitate formation, phase separation, or visible aggregation, even gelation. Heat-induced destabilization of milk can be modulated by several changes to the casein micelles and their surrounding serum environment: changes in $\mathrm{pH}$, calcium, and phosphate deposition on the micelles, or protein dephosphorylation, dissociation of caseins from the colloidal phase, molecular hydrolysis, and formation of protein aggregates through hydrophobic and covalent disulfide bonds (Fox, 1981).

In milk reconstituted from skim milk powder, a minimum in whey protein denaturation is observed at about 20\% solids (Anema, 1998). This is not necessarily the case for MPC, where the mineral balance and the ratio of protein versus other solids will depend on the processing conditions. In general, the heat stability of reconstituted protein concentrates is inversely proportional to their protein level in the powder (Crowley et al., 2014).

Heating at temperatures above $60^{\circ} \mathrm{C}$ causes unfolding and denaturation of whey proteins, with exposure of their reactive groups, causing protein-protein interactions and the formation of various complexes depending on their concentration, the presence of other proteins, or the environmental conditions (Anema, 1998). In skim milk, heating at $\mathrm{pH}$ below the native milk $\mathrm{pH}$ leads to a preferential attachment of the whey proteins on the surface of casein micelles, causing an increase in their apparent diameter (Kethireddipalli et al., 2011; Krishnakutti Nair et al., 2013). On the other hand, at a $\mathrm{pH}$ higher than 6.8 , there is an increase in the population of aggregates present in the continuous serum phase (Guyomarc'h et al., 2003). Approximately 70\% of the whey proteins are associated with the micelles at $\mathrm{pH} 6.5$, whereas at neutral $\mathrm{pH}$ and higher $\mathrm{pH}$ the associated portion is about $30 \%$ of the total whey proteins (Kethireddipalli et al., 2011). It has been widely demonstrated that the heat-induced complexes present in heated milk, as well as in fresh and reconstituted concentrates, are critical in imparting technological functionality (Lucey et al., 1998; Guyomarc'h et al., 2003), and in this context heat stability to the final product (Crowley et al., 2014; Renhe and Corredig, 2018).
As mentioned above, the processing conditions employed to prepare MPC will have profound consequences on the amount of soluble and colloidal ions, as well as the amount of caseins released in the soluble phase, along with buffering capacity of reconstituted suspensions. Mineral balance is critical to the thermal stability of MPC. It has been shown that during heating of skim milk the levels of serum phosphate and calcium decrease as these ions become insoluble, causing a decrease in overall negative charge and associated repulsion between protein particles, ultimately resulting in colloidal destabilization (Singh and Creamer, 1991).

Concentration of milk by UF will increase the buffering capacity of the milk concentrates, compared with unconcentrated milk. Figure 2 illustrates the difference in buffering index between skim milk and milk concentrated $4 \times$ (based on volume reduction). The use of $\mathrm{DF}$, in combination with UF, causes increased release of insoluble calcium, with no observed changes in the buffering capacity of the concentrates ( $\mathrm{Li}$ and Corredig, 2014). After heating, the concentrates show a slight shift of the buffering peak toward a lower $\mathrm{pH}$ (Figure 2 ). It is important to note that these results were obtained on fresh concentrates, and this may not be the case for reconstituted concentrates as more dissociation of colloidal calcium phosphate may occur during reconstitution (Lin et al., 2018).

In addition to changes in mineral balance, another factor that affects thermal stability is the presence of unsedimentable aggregates during concentration. Protein-protein interactions are affected by time, tem-

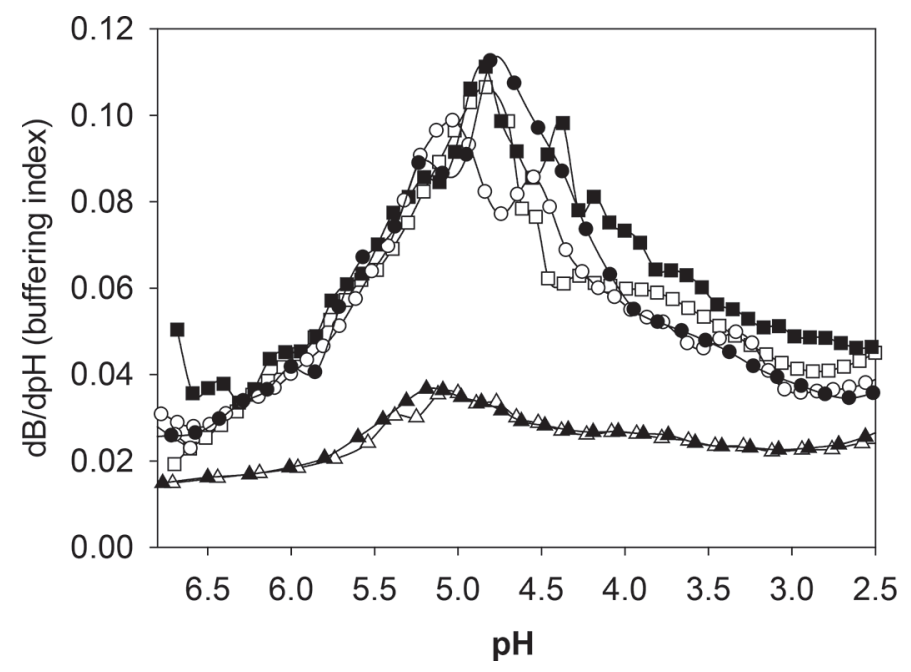

Figure 2. Buffering capacity curves [change in amount of acid $(\mathrm{mL})(\mathrm{dB})$ per change in $\mathrm{pH}(\mathrm{dpH})]$ of unheated (empty symbols) or heated $\left(80^{\circ} \mathrm{C}\right.$ for $15 \mathrm{~min}$ ) (filled symbols) $4 \times$ concentrates prepared either by UF (squares) or UF with diafiltration (circles), compared with skim milk (triangles). The samples were acidified from the initial $\mathrm{pH}$ of 6.8 to $\mathrm{pH} 2$ with $\mathrm{HCl}$. 
perature, rate of heating, $\mathrm{pH}$, and protein concentration ( $\mathrm{Li}$ et al., 2015). A recent study compared the heat-induced aggregates present in MPC obtained from heated and unheated milk, at native $\mathrm{pH}$, prepared by UF or UF combined with DF (Li et al., 2015). The composition of the unsedimentable fraction (separated at $25,000 \times g$ for $1 \mathrm{~h}$ at $20^{\circ} \mathrm{C}$ and subsequently filtered through $0.45 \mu \mathrm{m}$ ) was different between unheated UF concentrates or UF/DF concentrates heated at $90^{\circ} \mathrm{C}$ for $5 \mathrm{~min}$ (Figure 3). A shorter elution time signified the presence of larger aggregates in the soluble phase. Although the unheated fractions showed a similar level of soluble aggregates, eluting between 75 and $90 \mathrm{~min}$, after heating, there was a large population of aggregates with a large distribution eluting from 50 to 90 min. A much larger fraction of nonsedimentable protein was present in UF-DF heated concentrates, compared with UF concentrates. In all the concentrates, $\kappa-\mathrm{CN}$ and $\beta-L G$ were the main proteins present in the unsedimented fraction, but there were profound differences in the size and concentration of the soluble aggregates as a function of temperature ( $\mathrm{Li}$ et al., 2015).

Type and concentration of heat-induced aggregates in various types of milk concentrates and isolates are not fully understood. The differences in these aggregates may be one of the factors affecting heat stability of fresh and reconstituted retentates. It has been reported that reconstituted MPC with a high concentration of protein (MPC 80 and 90, which are subjected to extensive DF) show lower heat stability than MPC 70 after in container sterilization (Crowley et al., 2015b). The role of the partial disruption of caseins, the formation of aggregates, and of course the means of reconstitution and the re-equilibration of their colloidal and soluble calcium and phosphate fractions, will all play a role in the final heat stability.

Heating of concentrated milk causes an increase in the serum viscosity (Krishnakutti Nair et al., 2013). Whereas the ratio of whey proteins to caseins in the serum phase is unchanged when untreated milk is concentrated, milk heated at varying $\mathrm{pH}$ levels and subsequently concentrated shows a significant difference in the ratio of whey proteins to caseins in the serum phase. The highest soluble casein to whey protein ratio is observed when milk is heated at $\mathrm{pH} 6.4$ and then concentrated, while heat treatments at $\mathrm{pH} 6.7$ and 7.0 result in higher ratio of whey protein to soluble casein (Krishnakutti Nair et al., 2013). In reconstituted MPC, k-CN dissociation decreases with increasing protein content and increases with pH (Crowley et al., 2015a).

Excessive calcium activity has been attributed as a problem in heat stability of MPC with high protein concentration (Crowley et al., 2015a). Recently, calcium-depleted MPC have been suggested as possible

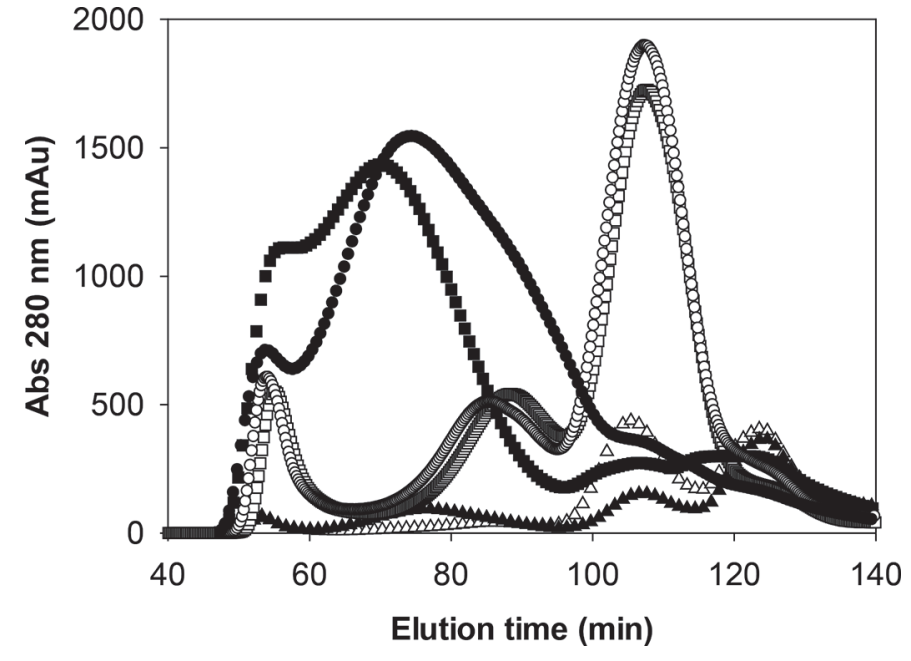

Figure 3. Size exclusion chromatography profiles of centrifugal supernatants obtained from unheated (empty symbols) or heated $\left(90^{\circ} \mathrm{C}\right.$ for $5 \mathrm{~min}$; filled symbols) milk samples concentrated $4 \times$ by UF (squares) or UF with diafiltration (circles). Skim milk supernatants are also shown (triangles). Supernatants were separated by centrifugation at $100,000 \times g$ for $1 \mathrm{~h}$ at $20^{\circ} \mathrm{C}$. Abs $=$ absorbance.

value added for ready to drink and enteral formulations (Eshpari et al., 2014; Marella et al., 2015; Pandalaneni et al., 2018); however, it is important to also control the reconstitution conditions, as this will further modify the ionic balance (Eshpari et al., 2014, 2015; Lin et al., 2018; Liu et al., 2019). Reconstituted MPC powders made with partially acidified milk containing lower soluble calcium and phosphate exhibit poor thermal stability compared with MPC powders made with milk at its natural pH (Eshpari et al., 2014). The thermal stability of the acidified MPC dispersions improves by restoration of $\mathrm{pH}$ and the serum composition through dialysis against milk, or using permeate as a reconstituting medium (Eshpari et al., 2014; Crowley et al., 2014; Lin et al., 2018; Pandalaneni et al., 2018). By comparing samples with similar $\mathrm{pH}$ and protein, calcium, and phosphate concentrations, it was shown that the presence of nonsedimentable caseins plays a major role in determining the thermal stability of these MPC dispersions, by assisting in stabilization of the colloidal suspension (Eshpari et al., 2014; Lin et al., 2018).

Because of their sensitivity to heat, removal of whey proteins has also been proposed as a way to obtain beverages with superior heat stability. Micellar casein concentrates and isolates have been proposed as an ideal ingredient for the development of dairy beverages. These are concentrates prepared with membrane filtration, but where the pore size of the membrane allows permeation of whey proteins. Studies have been conducted on the stability of these micellar casein concentrates at different $\mathrm{pH}$ values, variable calcium concen- 
tration and distribution, and the presence of chelators (de Kort et al., 2012; Sauer and Moraru, 2012; Renhe et al., 2018). These studies report poor heat stability of high protein solutions after reconstitution, and extra steps such as $\mathrm{pH}$ adjustment or addition of calcium chelators (or both) are necessary to achieve longer heat coagulation times and to avoid precipitation and coagulation during the commercial life of the product. The reason for the instability was not fully discussed, but it may be attributed to changes in the calcium activity. A study on fresh concentrates prepared by membrane filtration demonstrated major differences in heat stability between UF concentrates and concentrates with partially depleted whey proteins (Renhe and Corredig, 2018). The partial removal of whey proteins increases heat stability when the concentrates are compared with the UF concentrates, at same concentration factor and with similar serum composition (Renhe and Corredig, 2018). More work is needed to understand the differences in whey protein aggregation and the effect of reconstitution and mineral balance in these modified protein concentrates as there are clear discrepancies in the literature.

In summary, many studies have been carried out to understand the effect of thermal treatment on concentrates, but more attention needs be focused on the processing history and compositional differences, as these may be the key to discrepancies in literature reports. Because of the higher protein ratio or the lower lactose content, MPC or isolates are often the preferred ingredients for ready-to-drink beverages. It is known that heat stability of reconstituted concentrates can be improved with pre-heating of milk, by changing composition or by the addition of calcium chelating agents (Singh, 2004; de Kort et al., 2012; Lin et al., 2018; Renhe et al., 2018). It may be possible in the future to prepare MPC better tailored for heat stability, by better control of process conditions, for example, controlling the extent of calcium depletion, heating history, or the amount of DF. It is also important not to dismiss that drying conditions including, but not limited to feed temperature, solids level, inlet and outlet temperature, and dryer design, also critically affect the properties of the reconstituted MPC.

\section{Casein Micelle Gelation}

Milk protein concentrates and isolates are commonly used as functional ingredients in the standardization of milk in certain processes, to reduce the amount of whey co-products, or to create protein gels with higher protein concentrations than those prepared with skim milk. Although much is understood on the destabilization mechanisms leading to the formation of casein gels, the details of the aggregation behavior of casein micelles in concentrated systems are not fully known.

Key factors in understanding this behavior include volume fraction, linked to their decreased mobility and the increased opportunities for collisions between the casein micelles, the ratio between colloidal to soluble calcium and phosphate, the presence of soluble proteins in the continuous phase, the reactions between casein micelles and the other components (i.e., whey proteins), the intra-micellar interactions at the initial stages of the gelation, and the ability of the micelles to rearrange within the network. It cannot be sufficiently stressed that the processing history of the concentrates is critical.

The increase in volume fraction of the casein micelles will force the protein particles to collide and interact more frequently with each other (De Kruif, 1998). It has been hypothesized that the decreased distance may result in a partial collapse of the $\kappa-\mathrm{CN}$ layer, causing a decrease in steric repulsion forces (De Kruif, 1998). However, studies with fresh milk concentrates at constant $\mathrm{pH}$ have demonstrated that, regardless of the volume fraction of the caseins, the gelation point still occurs only when more than $85 \%$ of the $\kappa-\mathrm{CN}$ is hydrolyzed. Hence, a possible decrease in steric repulsion is not sufficient to cause a change in the rennet-induced aggregation mechanism (Sandra et al., 2011). The increased volume fraction has important consequences to the values of gel stiffness, as more concentrated mixtures will have a larger number of linkages in the gel network (Karlsson et al., 2007; Sandra et al., 2011).

The contributions of colloidal calcium phosphate and free calcium are critical to the viscoelastic properties of the final gels (Lucey and Horne, 2018). In particular, they affect not only the gelation mechanism but also further processing properties of the gels such as meltability or water-holding capacity (Choi et al., 2007; Sandra and Corredig, 2013). Furthermore, the release of colloidal calcium during acidification in acid-induced gels is an important mechanism that also affects the viscoelastic properties of the gels and the rearrangement of casein particles within the network (Le Graët and Gaucheron, 1999; Lucey, 2002), and concentrates show higher buffering capacity compared with skim milk.

Reconstituted MPC require a sufficient amount of calcium ions in solution to restore their chymosininduced gelation behavior (Martin et al., 2010; Sandra and Corredig, 2013). It has been shown that $2 \mathrm{mM}$ calcium (in the form of calcium chloride) needs to be added to milk concentrates to be able to form a selfsupporting gel network (Martin et al., 2010), but this may differ depending on the composition and history of the concentrates (Lin et al., 2018). Concentration 
of milk may cause partial disruption of casein micelles with an increase in the concentration of soluble caseins in the serum phase, either in fresh or reconstituted retentates. This will impair chymosin-induced aggregation (Gaygadzhiev et al., 2012). Addition of soluble calcium will restore the ability to gel, causing calcium induced precipitation of the unsedimentable casein fraction (Sandra and Corredig, 2013).

Acidification of the casein micelle suspensions leads to the release of colloidal calcium phosphate and a partial collapse of the hydrated polyelectrolyte layer, decreasing the steric repulsion forces (Lucey et al., 1996; Karlsson et al., 2007). Figure 4 illustrates the gelation behavior after addition of chymosin, in mixtures containing untreated skim milk with fresh $3 \times$ concentrates (1:1 addition) pre-acidified to various $\mathrm{pH}$ values. Concentrates were prepared as previously described (Zhao and Corredig, 2016a). Whereas the primary phase of the enzymatic-induced coagulation is not affected (data not shown), there are differences in the development of the elastic modulus depending on the original $\mathrm{pH}$ of the milk concentrates, and these differences cannot be only attributed to differences in $\mathrm{pH}$ of the mix. The addition of a pH-reduced, concentrated milk to skim milk improved the coagulation properties of milk, with a decrease in gelation time and a higher elastic modulus, compared with the mixtures kept at $\mathrm{pH}$ 6.8. It is not known if this behavior is different with different ratios of concentrates added, with differences in processing history or in reconstituted retentates. Furthermore, lit-

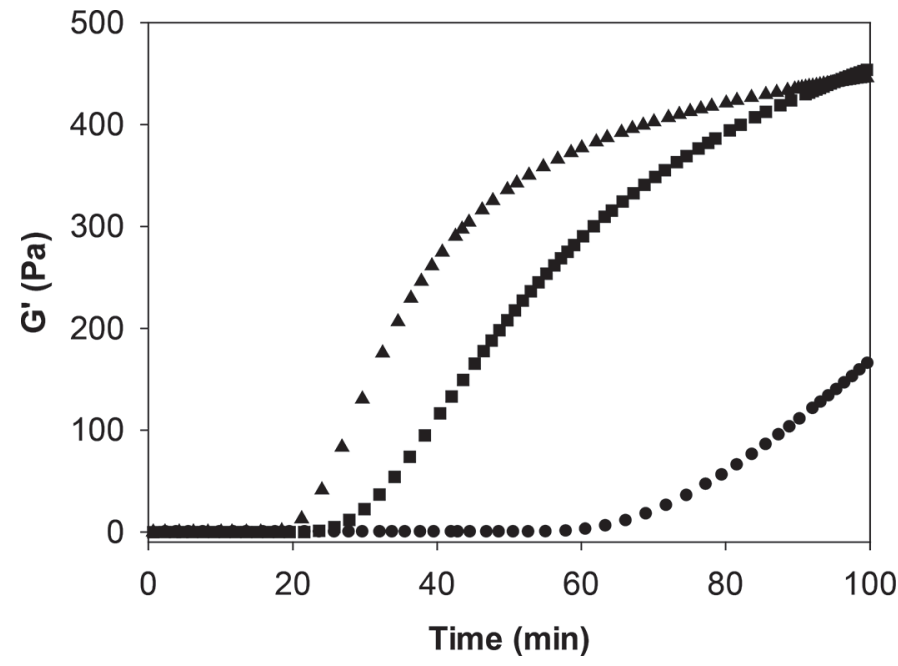

Figure 4. Development of elastic modulus $\left(\mathrm{G}^{\prime}\right)$ during chymosininduced gelation of milk samples obtained by mixing untreated skim milk (1:1 ratio) with $3 \times$ concentrated milk adjusted to $\mathrm{pH} 6.8$ (circles), 6.0 (squares), and 5.6 (triangles) with glucono-delta-lactone before concentration using osmotic stressing. The final mixtures contained about $6 \%$ total protein and a $\mathrm{pH}$ of $6.7,6.15$, and 5.9 , respectively.

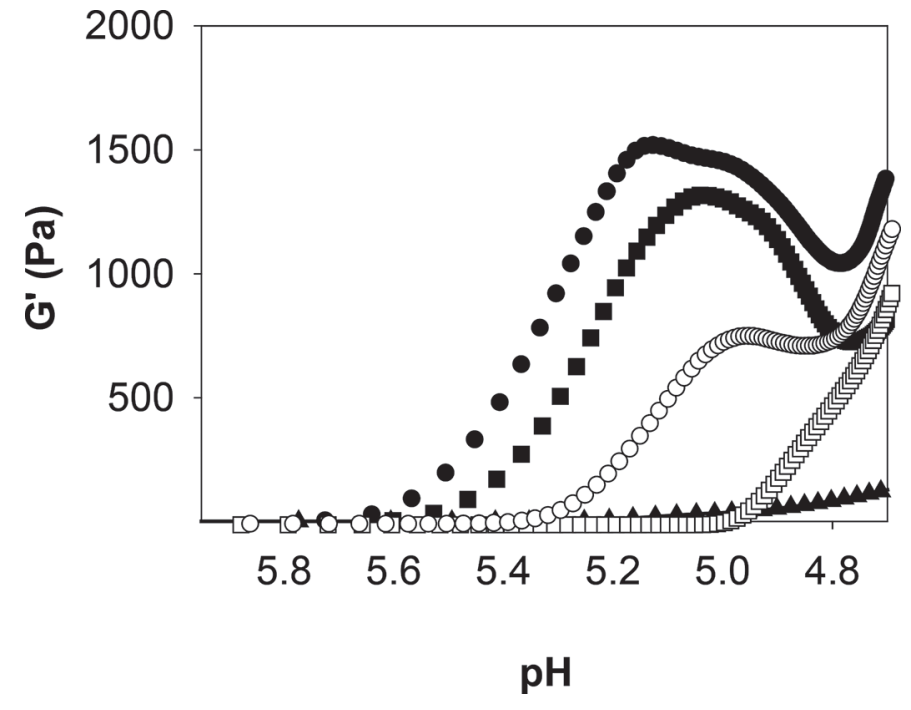

Figure 5. Development of the elastic modulus $\left(\mathrm{G}^{\prime}\right)$ during acidification using glucono-delta-lactone $(1.3 \%$ for skim milk, $3 \%$ for concentrates), for heated $\left(80^{\circ} \mathrm{C}\right.$ for $15 \mathrm{~min}$; filled symbols) and unheated (empty symbols) skim milk (triangles), or $4 \times$ concentrates using UF (squares) or UF combined with diafiltration (circles). Samples were prepared as described in $\mathrm{Li}$ and Corredig (2014) and incubated at $40^{\circ} \mathrm{C}$.

tle is known on the details of the aggregation behavior or the differences in the properties of the gels formed.

Differences in processing history also are critical in the formation of acid-induced gels. Solubilization of micellar calcium phosphate and partial destabilization of the casein micelles is more extensive when using reconstituted high protein MPC, as in these concentrates a higher extent of DF is applied (Meletharayil et al., 2018). The same authors demonstrated that by increasing the amount of nonmicellar casein the acid gelation properties can be modified, with the shift of the gelation $\mathrm{pH}$ to higher values, higher values of elastic modulus at end $\mathrm{pH}$, and a higher water-holding capacity of the gels (Meletharayil et al., 2018). Figure 5 illustrates the differences in the gel formation for $4 \times$ fresh MPC prepared either using UF or UF combined with DF (concentration based on volume reduction). It was suggested that the presence of different nonsedimentable aggregates ( $\mathrm{Li}$ et al., 2015) plays a major role in the higher $\mathrm{pH}$ of aggregation, as well as in the inflection point of the $\mathrm{G}^{\prime}$ versus time $\mathrm{pH}$ profiles seen in Figure 3, and also reported for high-protein MPC reconstituted in water (Lin et al., 2018).

\section{CONCLUSIONS}

In response to the increasing demand for high quality proteins in today's diet, MPC either fresh or in reconstituted form has been increasingly used in different 
food applications. Information on the processing behavior of milk as a function of the composition, processing history, and colloidal state of the casein micelles is still scarce. This work has demonstrated how understanding the details of the colloidal properties of casein micelles and their destabilization behavior as a function of processing history offers potential for innovation for both current and future processes and products. The alteration of protein ratios, ionic equilibrium, colloidal micellar structure, and the dynamic dissociation state of the micelles are key to provide concentrates with different processing functionalities. A better understanding of structure-functional changes will also allow improved control of quality and performance of these ingredients.

\section{ACKNOWLEDGMENTS}

The present work was funded by the Natural Sciences and Engineering Council of Canada (Ottawa) and the Ontario Dairy Council (Toronto). The support of the funding of the iFood Institute, Aarhus University, to M. Corredig is also acknowledged.

\section{REFERENCES}

Anema, S. G. 1998. Effect of milk concentration on heat-induced, pHdependent dissociation of casein from micelles in reconstituted skim milk at temperatures between 20 and $120^{\circ} \mathrm{C}$. J. Agric. Food Chem. 64:2299-2305.

Anema, S. G., and Y. Li. 2003. Effect of $\mathrm{pH}$ on the association of denatured whey proteins with casein micelles in heated reconstituted skim milk. J. Agric. Food Chem. 51:1640-1646.

Bouchoux, A., P. E. Cayemitte, J. Jardin, G. Gésan-Guiziou, and B. Cabane. 2009a. Casein micelle dispersions under osmotic stress. Biophys. J. 96:693-706.

Bouchoux, A., B. Debbou, G. Gésan-Guiziou, M. Famelart, J. Doublier, and B. Cabane. 2009b. Rheology and phase behavior of dense casein micelle dispersions. J. Chem. Phys. 131:165106-165116.

Bouchoux, A., G. Gésan-Guiziou, J. Pérez, and B. Cabane. 2010. How to squeeze a sponge: Casein micelles under osmotic stress, a SAXS study. Biophys. J. 99:3754-3762.

Choi, J., D. S. Horne, and J. A. Lucey. 2007. Effect of insoluble calcium concentration on rennet coagulation properties of milk. J. Dairy Sci. 90:2612-2623.

Crowley, S. V., M. Boudin, B. Chen, I. Gazi, T. Huppertz, A. L. Kelly, and J. A. O'Mahony. 2015a. Stability of milk protein concentrate suspensions to in-container sterilization heating conditions. Int. Dairy J. 50:45-49.

Crowley, S. V., B. Desautel, I. Gazi, A. L. Kelly, T. Huppertz, and J. A. O'Mahony. 2015b. Rehydration characteristics of milk protein concentrate powders. J. Food Eng. 149:105-113.

Crowley, S. V., A. L. Kelly, and J. A. O. Mahony. 2014. Heat stability of reconstituted milk protein concentrate powders. Int. Dairy J. 37:104-110.

Dahbi, L., M. Alexander, V. Trappe, J. K. G. Dhont, and P. Schurtenberger. 2010. Rheology and structural arrest of casein suspensions. J. Colloid Interface Sci. 342:564-570.

Dalgleish, D. G. 2011. On the structural models of bovine casein micelles - Review and possible improvements. Soft Matter 7:22652272 .

Dalgleish, D. G., M. Alexander, and M. Corredig. 2004. Studies of the acid gelation of milk using ultrasonic spectroscopy and diffusing wave spectroscopy. Food Hydrocoll. 18:747-755.
Dalgleish, D. G., and M. Corredig. 2012. The structure of the casein micelle of milk and its changes during processing. Annu. Rev. Food Sci. Technol. 3:449-467.

de Kort, E., M. Minor, T. Snoeren, T. van Hooijdonk, and E. van der Linden. 2012. Effect of calcium chelators on heat coagulation and heat-induced changes of concentrated micellar casein solutions: The role of calcium-ion activity and micellar integrity. Int. Dairy J. 26:112-119.

De Kruif, C. G. 1992. Casein micelles: Diffusivity as a function of renneting time. Langmuir 8:2932-2937.

De Kruif, C. G. 1998. Supra-aggregates of casein micelles as a prelude to coagulation. J. Dairy Sci. 81:3019-3028.

De Kruif, C. G., T. Huppertz, V. S. Urban, and A. V. Petukhov. 2012. Casein micelles and their internal structure. Adv. Colloid Interface Sci. 171-172:36-52.

De Kruif, C. G., and E. B. Zhulina. 1996. א-casein as a polyelectrolyte brush on the surface of casein micelles. Colloids Surf. A Physicochem. Eng. Asp. 117:151-159.

Deshpande, V. K., and M. K. Walsh. 2018. Effect of sonication on the viscosity of reconstituted skim milk powder and milk protein concentrate as influenced by solids concentration, temperature and sonication. Int. Dairy J. 78:122-129.

Donato, L., M. Alexander, and D. G. Dalgleish. 2007. Acid gelation in heated and unheated milks: Interactions between serum protein complexes and the surfaces of casein micelles. J. Agric. Food Chem. 55:4160-4168.

Donato, L., and D. G. Dalgleish. 2006. Effect of the $\mathrm{pH}$ of heating on the qualitative and quantitative compositions of the sera of reconstituted skim milks and on the mechanisms of formation of soluble aggregates. J. Agric. Food Chem. 54:7804-7811.

Eshpari, H., P. S. Tong, and M. Corredig. 2014. Changes in the physical properties, solubility, and heat stability of milk protein concentrates prepared from partially acidified milk. J. Dairy Sci. 97:7394-7401.

Eshpari, H., P. S. Tong, and M. Corredig. 2015. Partial calcium depletion during membrane filtration affects gelation of reconstituted milk protein concentrates. J. Dairy Sci. 98:8454-8463.

Ferrer, M. A., M. Alexander, and M. Corredig. 2011. Does ultrafiltration have a lasting effect on the physico-chemical properties of the casein micelles? Dairy Sci. Technol. 91:151-170.

Fox, P. F. 1981. Heat-induced changes in milk preceding coagulation. J. Dairy Sci. 64:2127-2137.

Gaygadzhiev, Z., V. Massel, M. Alexander, and M. Corredig. 2012. Addition of sodium caseinate to skim milk inhibits rennet-induced aggregation of casein micelles. Food Hydrocoll. 26:405-411.

Gazi, I., and T. Huppertz. 2015. Influence of protein content and storage conditions on the solubility of caseins and whey proteins in milk protein concentrates. Int. Dairy J. 46:22-30.

Guyomarc'h, F., A. Law, and D. G. Dalgleish. 2003. Formation of soluble and micelle-bound protein aggregates in heated milk. J. Agric. Food Chem. 51:4652-4660.

Havea, P. 2006. Protein interactions in milk protein concentrate powders. Int. Dairy J. 16:415-422.

Holt, C. 1992. Structure and stability of bovine casein micelles. Adv. Protein Chem. 43:63-151.

Holt, C. 2004. An equilibrium thermodynamic model of the sequestration of calcium phosphate by casein micelles and its application to the calculation of the partition of salts in milk. Eur. Biophys. J. 33:421-434.

Holt, C., J. A. Carver, H. Ecroyd, and D. C. Thorn. 2013. Invited review: Caseins and casein micelle: their biological functions, structures and behavior in foods. J. Dairy Sci. 96:6127-6146.

Horne, D. 2003. Casein micelles as hard spheres: Limitations of the model in acidified gel formation. Colloids Surf. A Physicochem. Eng. Asp. 213:255-263.

Huppertz, T., I. Gazi, H. Luyten, H. Nieuwenjuijse, A. Alting, and E. Schokker. 2017. Hydration of casein micelles and caseinates: Implications for casein micelle structure. Int. Dairy J. 74:1-11.

Karlsson, A. O., R. Ipsen, and Y. Ardö. 2007. Rheological properties and microstructure during rennet induced coagulation of UF concentrated skim milk. Int. Dairy J. 17:674-682. 
Karlsson, A. O., R. Ipsen, K. Schrader, and Y. Ardö. 2005. Relationship between physical properties of casein micelles and rheology of skim milk concentrate. J. Dairy Sci. 88:3784-3797.

Kethireddipalli, P., A. R. Hill, and D. G. Dalgleish. 2011. Interaction between casein micelles and whey protein/ $/$-casein complexes during renneting of heat-treated reconstituted skim milk powder and casein micelle/serum mixtures. J. Agric. Food Chem. 59:14421448.

Krishnankutti Nair, P., M. Alexander, D. G. Dalgleish, and M. Corredig. 2014. Physico-chemical properties of casein micelles in unheated skim milk concentrated by osmotic stressing: Interactions and changes in the composition of the serum phase. Food Hydrocoll. $34: 46-53$.

Krishnankutty Nair, P., and M. Corredig. 2015. Rennet-induced gelation of concentrated milk in the presence of sodium caseinate: Differences between milk concentration using ultrafiltration and osmotic stressing. J. Dairy Sci. 98:27-36.

Krishnankutti Nair, P., D. G. Dalgleish, and M. Corredig. 2013. Colloidal properties of concentrated heated milk. Soft Matter 9:38153824.

Le Graët, Y., and F. Gaucheron. 1999. pH-induced solubilization of minerals from casein micelles: Influence of casein concentration and ionic strength. J. Dairy Res. 66:215-224.

Li, Y., and M. Corredig. 2014. Calcium release from milk concentrated by ultrafiltration and diafiltration. J. Dairy Sci. 97:5294-5302.

Li, Y., D. G. Dalgleish, and M. Corredig. 2015. Influence of heating treatment and membrane concentration on the formation of soluble aggregates. Food Res. Int. 76:309-316.

Lin, Y., A. L. Kelly, J. A. O’Mahony, and T. P. Guinee. 2018. Effects of milk heat treatment and solvent composition on physicochemical and selected functional characteristics of milk protein concentrate. J. Dairy Sci. 101:6799-6813.

Liu, D., J. Zhang, T. Yang, X. Liu, Y. Hemar, J. M. Regenstein, and P. Zhou. 2019. Effects of skim milk pre-acidification and retentate pH-restoration on spray-drying performance, physicochemical and functional properties of milk protein concentrates. Food Chem. 272:539-548

Liu, D. Z., D. E. Dunstan, and G. J. O. Martin. 2012. Evaporative concentration of skimmed milk: Effect on casein micelle hydration, composition, and size. Food Chem. 134:1446-1452.

Lucey, J., C. Gorry, B. O. Kennedy, M. Kalab, and P. F. Fox. 1996. Effect of acidification and neutralization of milk on some physicochemical properties of casein micelles. Int. Dairy J. 6:257-272.

Lucey, J. A. 2002. Formation and physical properties of milk protein gels. J. Dairy Sci. 85:281-294.

Lucey, J. A., and D. S. Horne. 2018. Perspectives on casein interactions. Int. Dairy J. 85:56-65.

Lucey, J. A., M. Tamehana, H. Singh, and P. A. Munro. 1998. Effect of interactions between denatured whey proteins and casein micelles on the formation and rheological properties of acid skim milk gels. J. Dairy Res. 65:555-567.

Marella, C., P. Salunke, A. C. Biswas, A. Kommineni, and L. E. Metzger. 2015. Manufacture of modified milk protein concentrate utilizing injection of carbon dioxide. J. Dairy Sci. 98:3577-3589.

Martin, G. J. O., R. P. W. Williams, and D. E. Dunstan. 2010. Effect of manufacture and reconstitution of milk protein concentrate powder on the size and rennet gelation behaviour of casein micelles. Int. Dairy J. 20:128-131.

Meletharayil, G. H., H. A. Patel, L. E. Metzger, C. Marella, and T. Huppertz. 2018. Influence of partially demineralized milk proteins on rheological properties and microstructure of acid gels. J. Dairy Sci. 101:1864-1871.

Mendoza, C. I., and I. Santamaría-Holek. 2009. The rheology of hard sphere suspensions at arbitrary volume fractions: An improved differential viscosity model. J. Chem. Phys. 130:044904.
Morris, G. A., T. J. Foster, and S. E. Harding. 2000. Further observations on the size, shape, and hydration of casein micelles from novel analytical ultracentrifuge and capillary viscometry approaches. Biomacromolecules 1:764-767.

Nöbel, S., K. Weidendorfer, and J. Hinrichs. 2012. Apparent voluminosity of casein micelles determined by rheometry. J. Colloid Interface Sci. 386:174-180.

Pandalaneni, K., J. Amarmcharla, C. Marella, and L. E. Metzger. 2018. Influence of milk protein concentrates with modified calcium content on enteral dairy beverage formulations: Physicochemical properties. J. Dairy Sci. 101:9714-9724.

Qu, P., A. Bouchoux, and G. Gésan-Guiziou. 2015. On the cohesive properties of casein micelles in dense systems. Food Hydrocoll. 43:753-762.

Ramchandran, L., X. Luo, and T. Vaisljevic. 2017. Effect of chelators on functionality of milk protein concentrates obtained by ultrafiltration at a constant $\mathrm{pH}$ and temperature. J. Dairy Res. 84:471-478.

Renhe, I. R. T., and M. Corredig. 2018. Effect of partial whey protein depletion during membrane filtration on thermal stability of milk concentrates. J. Dairy Sci. 101:8757-8766.

Renhe, I. R. T., L. M. Indris, and M. Corredig. 2018. Effect of calcium chelators on heat stability and heat-induced changes in milk microfiltered concentrates. Int. Dairy J. 82:4-10.

Sandra, S., M. Alexander, and D. G. Dalgleish. 2007. The rennet coagulation mechanism of skim milk as observed by transmission diffusing wave spectroscopy. J. Colloid Interface Sci. 308:364-373.

Sandra, S., C. Cooper, M. Alexander, and M. Corredig. 2011. Coagulation properties of ultrafiltered milk retentates measured using rheology and diffusing wave spectroscopy. Food Res. Int. 44:951-956.

Sandra, S., and M. Corredig. 2013. Rennet induced gelation of reconstituted milk protein concentrates: The role of calcium and soluble proteins during reconstitution. Int. Dairy J. 29:68-74.

Sauer, A., and C. I. Moraru. 2012. Heat stability of micellar casein concentrates as affected by temperature and pH. J. Dairy Sci 95:6339-6350.

Schokker, E. P., J. S. Church, J. P. Mata, E. P. Gilbert, A. Puvanenthiran, and P. Udabage. 2011. Reconstitution properties of micellar casein powder: Effects of composition and storage. Int. Dairy J. 21:877-886.

Shuck, P., A. Davenel, F. Mariette, V. Briard, S. Mejean, and M. Piot. 2002. Rehydration of casein powders: Effects of added mineral salts and salt addition methods on water transfer. Int. Dairy J. $12: 51-57$

Sikand, V., P. S. Tong, and J. Walker. 2013. Effect of adding salt during the diafiltration step of milk protein concentrate powder manufacture on mineral and soluble protein composition. Dairy Sci. Technol. 93:401-413.

Singh, H. 2004. Heat stability of milk. Int. J. Dairy Technol. 57:111119.

Singh, H., and L. K. Creamer. 1991. Influence of concentration of milk solids on the dissociation of micellar k-casein on heating reconstituted milk at $120^{\circ}$ C. J. Dairy Res. 58:99-105.

Snoeren, T., A. Damman, and H. Klok. 1982. The viscosity of skimmilk concentrates. Neth. Milk Dairy J. 36:305-316.

Walstra, P. 1979. The voluminosity of bovine casein micelles and some of its implications. J. Dairy Res. 46:317-323.

Zhao, Z., and M. Corredig. 2016a. Colloidal properties of casein micelles suspensions as a function of $\mathrm{pH}$ during concentration by osmotic stressing. Food Hydrocoll. 60:445-452

Zhao, Z., and M. Corredig. 2016b. Influence of sodium chloride on the colloidal and rennet coagulation properties of concentrated casein micelle suspensions. J. Dairy Sci. 99:6036-6045. 